\title{
INTERNATIONAL DECOMMISSIONING SYMPOSIUM 2000
}

\section{IDS 2000}

Principal Investigator: M. A. Ebadian, Ph.D. Hemispheric Center for Environmental Technology Florida International University

Prepared for:

U.S. Department of Energy Office of Environmental Management

Office of Site Closure and Oak Ridge Operations Office Office of Assets Utilization

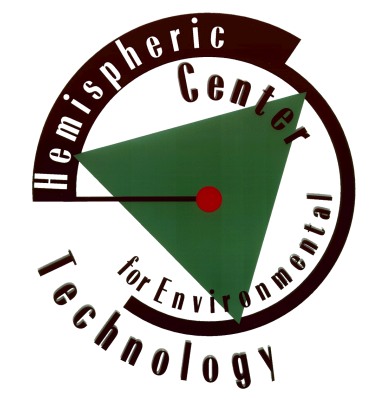




\section{DISCLAIMER}

This report was prepared as an account of work sponsored by an agency of the United States government. Neither the United States government nor any agency thereof, nor any of their employees, nor any of its contractors, subcontractors, nor their employees makes any warranty, express or implied, or assumes any legal liability or responsibility for the accuracy, completeness, or usefulness of any information, apparatus, product, or process disclosed, or represents that its use would not infringe upon privately owned rights. Reference herein to any specific commercial product, process, or service by trade name, trademark, manufacturer, or otherwise does not necessarily constitute or imply its endorsement, recommendation, or favoring by the United States government or any other agency thereof. The views and opinions of authors expressed herein do not necessarily state or reflect those of the United States government or any agency thereof. 


\title{
INTERNATIONAL DECOMMISSIONING SYMPOSIUM 2000 \\ (IDS 2000)
}

\author{
Principal Investigator \\ M. A. Ebadian, Ph.D. \\ Hemispheric Center for Environmental Technology \\ Florida International University \\ Miami, FL 33174
}

January 2001

Prepared for:

U.S. Department of Energy

Office of Environmental Management

Office of Site Closure

and

Oak Ridge Operations Office

Office of Assets Utilization

U.S. Department of Energy

Under Grant No. DE-FG21-95EW55094 
This report is based on work supported by the U.S. Department of Energy, Office of Environmental Management and its Office of Site Closure, and the Oak Ridge Operations Office and its Office of Assets Utilization. On behalf of Florida International University and the Hemispheric Center for Environmental Technology, the Principal Investigator would like to express appreciation for the support received in the execution of this scope of work.

On behalf of the International Decommissioning Symposium 2000, DOE-HQ/EM support was especially demonstrated by Dr. Carolyn Huntoon, James Fiore, William Murphie, Judson Lilly, Gerald Boyd, and Elizabeth O’Malley.

As the conference host, DOE- Oak Ridge Operations Office provided direct support to task management and execution. The efforts by Leah Dever, Robert Brown, Dr. Vincent Adams, Richard Meehan, and Marvin Bennett are acknowledged herewith. Additionally, the support by the Bechtel Jacobs Company, including Joe Nemec, Steve Houser, and Bill Biloski, is recognized.

The international support of the International Atomic Energy Agency (IAEA) in the development of the symposium was greatly appreciated. The significant involvement of Dr. Michele Laraia contributed to the global perspective of the technical program.

Special recognition for program development and support goes to DOE's National Energy Technology Laboratory and the contributions of Robert Bedick, E. Jane Powell, Steven Bossart, and John Duda, and to the unwavering support of the late Dr. Paul Hart. 


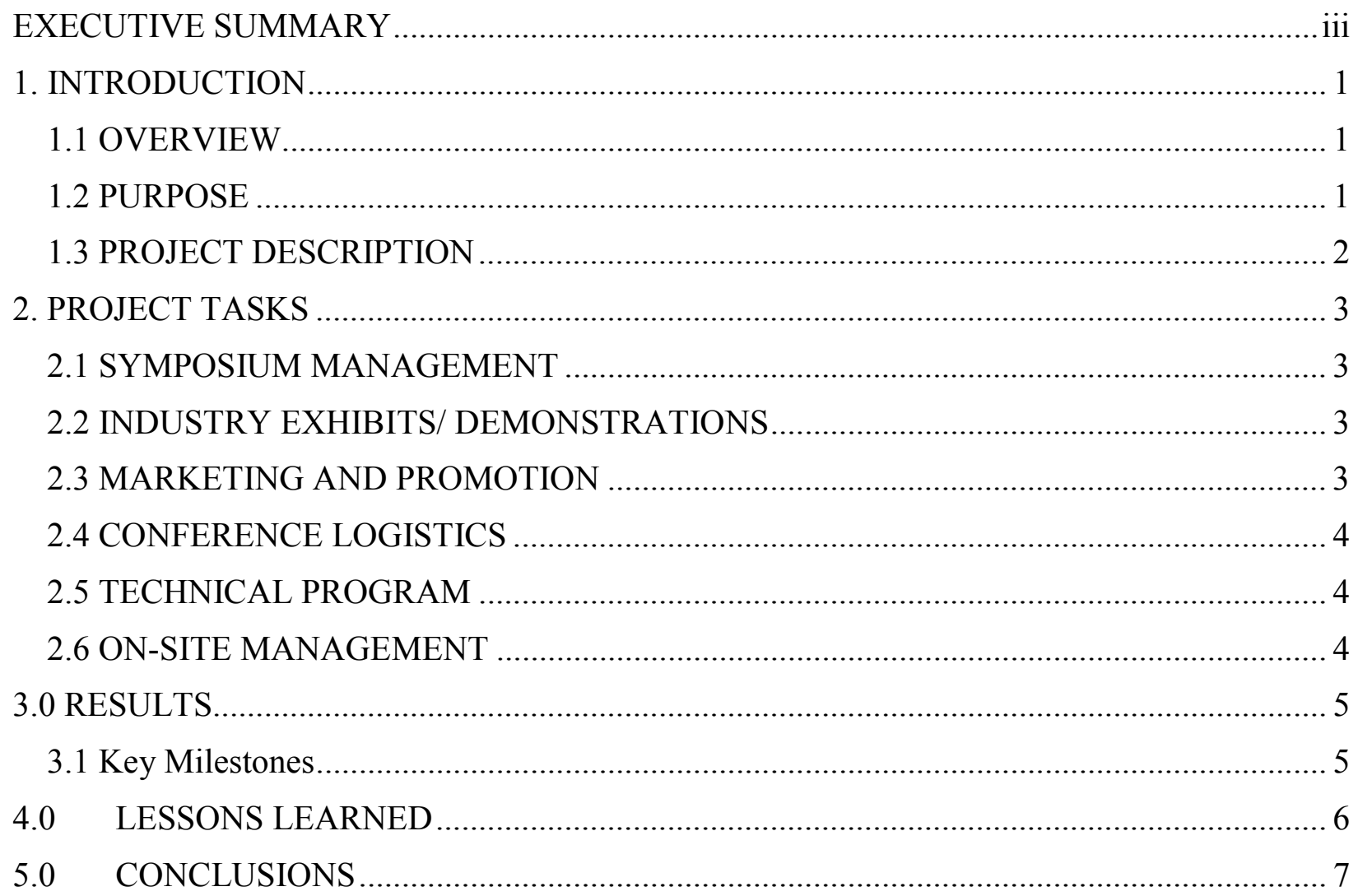




\section{EXECUTIVE SUMMARY}

U.S. Department of Energy (DOE) is chartered with the responsibility for management and resolution of federal environmental and waste concerns associated with the operation and shutdown of nuclear systems. During the 1980s, DOE supported and developed new technologies to meet significant technical and economic challenges to accomplish the effective environmental restoration and remediation of DOE facilities. Per DOE Paths to Closure documentation, the federal government estimated that more than 7,000 DOE facilities require environmental action, with costs of approximately $\$ 147$ billion and a schedule extending through 2070 .

Beyond DOE and other government operations, cost projections for the decommissioning of private and commercial nuclear utility facilities worldwide could exceed \$100,000,000. A 1997 analysis of the world decommissioning market through 2050, including defense facilities, commercial nuclear facilities, and fuel cycle facilities, estimated it at one trillion dollars. Market demand of this size is attractive to nuclear industry suppliers who have developed specialized skills, technologies, and goods and services for remediation. Federal, commercial, and international facilities represent a global business opportunity for the restoration/decommissioning industry.

In this context, the International Decommissioning Symposium (IDS), held June 12-16, 2000, in Knoxville, TN, provided a forum for government and industry to develop partnerships for environmental restoration. The fourth of a series covering an 18-year period, it provided a venue to showcase decommissioning experience and emerging decommissioning technologies.

At IDS 2000, there were 985 registrants from industry, government, and academia. More than 27 technical sessions resulted in the delivery of 144 technical and management presentations. Six panel sessions, involving over 36 subject matter experts, provided in-depth perspective to D\&D issues. With 100 exhibit and program booths, the exhibition area was responsive to problemholder and vendor discussion. The 9 outdoor technology demonstrations created a dynamic, and in some instances, a hands-on exchange between the potential client, vendor, and the demonstrated equipment.

The symposium closed with the recognition that continuing challenges lay ahead in decommissioning, including identification of methods to reduce costs, labor, and time in decommissioning activities. The areas of decommissioning, recycling, reindustrialization; worker safety; surveillance and maintenance requirements to minimize hazards; and site and facility release standards remain key focus issues. There is an indication that soil and groundwater cleanup will be a major future focus in site decommissioning, providing additional challenges. 


\subsection{INTRODUCTION}

\subsection{OVERVIEW}

The end of the Cold War stimulated the examination of national security programs, including nuclear weapons production, and initiated the distribution of "peace dividend" benefits to other areas, including environmental problems in both the Federal and the private arena. Within the United States, the Department of Energy (DOE) was chartered with the responsibility for management and resolution of federal environmental and waste concerns. During the 1980s, DOE supported and developed new technologies to meet the significant technical and economic challenges to effective environmental restoration and remediation of DOE facilities. The federal government has estimated that more than 7,000 DOE facilities require environmental action with costs of approximately $\$ 97$ billion and a schedule extending through 2070 .

Beyond DOE and other government operations, cost projections for the decommissioning of private and commercial nuclear utility facilities, worldwide, are expected to be of a significantly larger scale. Market demand of this size is attractive to nuclear industry suppliers who have developed specialized skills, technologies, and goods and services for remediation as well as those entities involved in DOE-sponsored technology development. Federal, commercial, and international facilities represent a global business opportunity for the restoration/ decommissioning industry.

Concurrent with the recognition that appropriate environmental response strategies were required to meet the challenge, a concept for International Decommissioning Symposia emerged in 1981 between DOE and the International Atomic Energy Agency (IAEA). The strategic drivers for the Symposia concept were the maturation of nuclear facilities, under-developed industrial response capability, and global decommissioning information and technology transfer. Subsequently, symposiums were held in 1982, 1987, 1994, and now 2000.

The fourth International Decommissioning Symposium will provide the avenue needed in developing partnerships for environmental restoration between government and industry around the world. The symposium will be an ideal forum to showcase available decommissioning skills and emerging decommissioning technologies. The IDS 2000 will foster relationships on applied decommissioning business practices and technologies, ones that demonstrate real economic, safety, or qualitative value. The IDS 2000 will reinforce DOE's vision and commitment to efficient decommissioning progress, technology development and transfer, and business partnerships.

The IDS 2000 will provide a forum for introducing environmental programs, demonstrating the benefits and effectiveness of environmental technologies, reviewing international environmental restoration progress, examining environmental needs, and establishing bases for information exchange and business development.

\subsection{PURPOSE}

The purpose of IDS 2000 was to deliver a world-class conference on applicable global environmental issues. The objective of this conference was to publicize environmental progress of individual countries, to provide a forum for technology developer and problem-holder interaction, to facilitate environmental and technology discussions between the commercial and 
financial communities, and to accommodate information and education exchange between governments, industries, universities, and scientists.

\subsection{PROJECT DESCRIPTION}

The scope of this project included the planning and execution of an international conference on the decommissioning of nuclear facilities, and the providing of a business forum for vendors and participants sufficient to attract service providers, technology developers, and the business and financial communities. These groups, when working together with attendees from regulatory organizations and government decision-maker groups, provide an opportunity to more effectively and efficiently expedite the decommissioning projects. The key components of the Symposium were as follow:

- Technical Conference Program

- Vendor Exhibits/Trade Show

- Technology Demonstrations/Simulations

- Oak Ridge Site Decommissioning Operations Tour.

The goals of the International Decommissioning Symposium included the following:

1. A four-day conference on environmental restoration, with emphasis on decommissioning.

2. A forum for a global environmental program statement, with details on problems and needs as well as technology and service performance methods.

3. A forum for information exchange among appropriate departments and international governmental contacts and agencies.

4. Specific and crosscutting forums of interest for significant target participants, such as universities, national laboratories, internationals, technology developers, and commercial nuclear interests.

5. A forum for business development and information exchange between the technology developers, industry, financial entities, and international participants.

6. A targeted participation of 800-1000 attendees.

7. Industrial representation of 70-100 domestic and international companies.

8. International representation of 20 countries.

9. 70-100 vendor exhibits and demonstrations/simulations.

10. 100 papers for presentation and poster sessions. 


\subsection{PROJECT TASKS}

The following major tasks delineate the work scope performed for the International Decommissioning Symposium. Descriptions of each task and subtask are provided below.

\subsection{SYMPOSIUM MANAGEMENT}

This task provided for overall symposium planning, management, and control. This task represented symposium management activities that included conference plan development, steering committee management, conference policy development, coordination of conference elements, recruitment of dignitaries and speakers, corporate sponsorships, on-site management, and project closeout activities. Task elements were as follow:

1. Conference Planning

2. Steering Committee Formation and Management

3. Conference Policies Development

4. Conference Management Plan Development

5. Performance Monitoring

6. Conference Management and Coordination

7. VIP Recruitment

8. Conference Reporting and Closeout.

\subsection{INDUSTRY EXHIBITS/ DEMONSTRATIONS}

This task provided for the planning, management, and execution of the industry trade show of exhibits and demonstrations. Key activities within this task were trade show planning, prospect development and marketing, and trade show management. Task elements were as follow:

1. Trade Show Planning

2. Trade Show Logistics

3. Industry Exhibitor/Demonstration Prospects

4. Exhibitor/Sponsor Marketing

5. Exhibit Management and Coordination.

\subsection{MARKETING AND PROMOTION}

This task encompassed the development and marketing activities for symposium advertising to target attendees and participants. Included within this task were marketing strategy and plan development, public and media relations, promotional materials, direct marketing activities, targeted sales calls, and electronic or "virtual marketing" that used Internet websites and online capacities to attract and register attendees. Task elements were as follow:

1. Marketing and Promotion Management

2. Marketing Strategy and Plan Development

3. Public/Media Relations

4. Promotional Materials Development

6. Marketing Execution. 


\subsection{CONFERENCE LOGISTICS}

This task provided for the management of conference logistics, which include facility management, contracts, reservations, administrative management and tracking systems, symposium proceedings, speaker management, and appropriate special event and guest programs. Task elements were as follow:

1. Conference Logistics Management

2. Administrative Tracking Systems Design

3. Logo/Slogan Design for Signage

4. Pre-conference Interest Survey

5. Conference Program Development and Dissemination

6. Conference Proceedings

7. VIP Press Conferences.

\subsection{TECHNICAL PROGRAM}

This task provided for the management and execution of the conference technical program. Key activities within this task included technical program planning and management, program committee development and management, speaker and poster program development, international representation, keynote recruitment, and program coordination with other conference elements. Task elements were as follow:

1. Technical Program Management

2. Committee Development

3. Speaker Program Development

4. Poster Session Development

5. Keynote/Headliner Recruitment.

\subsection{ON-SITE MANAGEMENT}

This task integrated the functions necessary to stage and execute the symposium. Resident within this task were conference support staffing, design and management of conference registration and administrative support functions, media oversight, and specific conference management including facilities and conference support subcontracts. Task elements included

1. Conference Support Staff Management

2. Registration and Administrative Support Functions

3. On-Site Conference Management

4. Media Management. 


\subsection{RESULTS}

The International Decommissioning Symposium was successfully conducted on June 12, 2000 to June 16, 2000, with 985 registrants. More than 27 technical sessions resulted in the delivery of 144 technical and management presentations. Six panel sessions, involving over 36 subject matter experts, provided in-depth perspective to D\&D issues. With 100 exhibit and program booths, the exhibition area was responsive to problem-holder and vendor discussion. The 9 outdoor technology demonstrations created a dynamic, and in some instances, a hands-on exchange between the potential client, vendor, and the demonstrated equipment.

The six project milestones shown in the following table were completed as indicated. Milestone dates were incrementally revised with client approval, as necessary to reflect the on-going effort of project team members to respond to actual participant response and performance conditions.

\subsection{KEY MILESTONES}

\begin{tabular}{|l|l|}
\hline Milestone & Completion Date \\
\hline I002-M1 Acceptance notification for papers & $1 / 21 / 00$ \\
\hline I002-M2 Final Agenda & $3 / 01 / 00$ \\
\hline I002-M3 Registration/Program Brochures & $3 / 20 / 00$ \\
\hline I002-M4 Technology Demonstrations Selected & $4 / 03 / 00$ \\
\hline I002-M5 Presentation Final Papers Due & $4 / 07 / 00$ \\
\hline I002-M6 Conference Proceedings & $8 / 31 / 00$ \\
\hline
\end{tabular}




\subsection{LESSONS LEARNED}

A number of lessons learned were identified during the development and execution of this task. Comments on problematic issues and strategic confirmation are provided as follow:

1. To the extent possible, meetings of this targeted size, marketing complexity, and specialized participation focus should anticipate a planning, development, and execution window of 18 to 24 months.

2. To the extent possible, the selection of the conference date and location should achieve separation from other competing meetings to maximize participation and assure currency of technical presentations. Competing national meetings during the weeks preceding and following IDS 2000 affected attendee and exhibitor participation.

3. To achieve the highest quality product, the involvement of sponsorship staff is essential to successful product delivery. The participation of the DOE-HQ/ORO/NETL staff, IAEA, and the Management and Integration Contractor in its development was essential to the success of IDS 2000 .

4. Commitment to participate by keynote speakers can be challenging to the technical program development committee. IDS 2000 was affected by the national election campaigns, as well as Departmental issues that required prioritized response by invited IDS 2000 speakers. Program planning requires third and fourth alternate depth of selection to assure response capability and conference delivery.

5. Government guidelines should be reviewed and incorporated into the execution plan. Performance strategies should be founded on the expectation of post-event audit and examination, and the acceptability of those strategies to meet the intent of the guidelines.

6. Logistics planning and hall layout requires consistency from host site conference services staff. Planning and layout should accommodate the potential for inappropriate entry points resulting in exhibit damage. Appropriate door security or signage is recommended.

7. To maximize conference effectiveness, event closure should be scheduled by Thursday of the performance week.

8. Appropriate planning, space, and utility services can attract outdoor technology vendor participation and create a highly interactive, attendee-vendor exchange. 


\subsection{CONCLUSIONS}

The International Decommissioning Symposium 2000 was held in Knoxville, Tennessee, as scheduled. As noted in the conference proceedings, many participants considered IDS 2000 a success. Some participants expressed the hope that a continuing information exchange on decommissioning progress be achieved. 